\title{
Probability of fire spread between vehicles in car parking buildings
}

\section{ABSTRACT}

Over recent years, performance-based design approach has gained acceptance in the engineering community around the world. This has prompted an expanded demand in engineering approaches to the assessment of fire safety in structures. Two arising questions in designing car parking buildings are (1) if there had been another vehicle parked next to or a space away from the van would the fire have spread given no interruption by firefighters and/or fire suppression systems? (2) If so, what is the probability that the spread occurs? This work quantitatively assesses these questions using recent research into the risk-based design of car parking buildings. The probability of fire spread is formulated using the knowledge of the possible rate of heat release outputs from single passenger vehicles coupled with a prediction of time to ignition. There are two scenarios considered for the assessment, either where the vehicles are parked next to each other or where the vehicles are parked one space apart. The analysis shows that the probability of fire spreading to a vehicle in an adjacent space $0.63-0.90$ while when there is a space in between, the highest probability of fire spread is 0.23 but spread may not occur at all.

Keyword: Vehicle fire; Car parks; Probability; Fire spread; Performance based design 